\title{
PENGARUH METODE DEMONSTRASI DENGAN MEDIA KONKRIT TERHADAP PEMAHAMAN KONSEP GERAK BENDA
}

\author{
Rizka Janawati Mita Arsih ${ }^{1}$ Agus Budi Santosa ${ }^{2}$ Nanda William $^{3}$ \\ STKIP PGRI Trenggalek \\ Email: ${ }^{1}$ rizkamita934@gmail.com, ${ }^{2}$ agus.budiku@gmai.com, ${ }^{3}$ williamnanda1@gmail.com
}

\begin{abstract}
Abstrak
Penelitian ini bertujuan untuk mengetahui seberapa pengaruh metode demonstrasi terhadap pemahaman konsep gerak benda pada pembelajaran IPA kelas IV SDN 3 Gandusari semester genap tahun pelajaran 2019/2020. Peneltian ini yang digunakan yaitu kuantitatif dengan jenis penelitian eksperimen. Populasi dalam penelitian ini seluruh siswa kelas IV dengan jumlah 10 siswa. Sedangkan sampel yang diambil pada penelitian ini 10 siswa. Metode pengumpulan data yang digunakan berupa tes. Tes yang digunakan untuk memperoleh data merupakan pretest dan posttest. Bentuk instrumen yang digunakan yaitu pilihan ganda dengan jumlah soal 20 item. Berdasarkan analisis yang telah diperoleh dari uji normalitas dengan menggunakan uji Shapiro-Wilk pretest signifikan sebesar 0,215>0,05. Jadi dapat disimpulkan bahwa hasil tersebut berdistribusi normal. Sedangkan untuk nilai posttest signifikan $0,311>0,05$. Jadi dapat disimpulkan bahwa hasil tersebut berdistribusi normal. Sedangkan untuk hasil uji homogenitas diketahui nilai signifikansi Based on Mean 0,206 > 0,05. Sehingga dapat disimpulkan bahwa varian data pretest dan posttest adalah homogen (sama). Untuk pengujian hipotesis menggunakan uji paired sample test diperoleh nilai sig. (2-tailed) pretest dan posttest 0,000 . Sesuai dengan uji pair sample $t$-test bahwa nilai sig. (2-tailed) $<0,05$ maka dapat disimpulkan bahwa terdapat perbedaan antara hasil belajar siswa pada data pretest dan posttest. Dengan demikian hasil dari penelitian ini dapat disimpulkan bahwa terdapat pengaruh metode demonstrasi terhadap pemahaman konsep gerak benda pada pembelajaran IPA siswa kelas IV SDN 3 Gandusari semester genap tahun pelajaran 2019/2020.
\end{abstract}

Kata Kunci : Metode Demonstrasi, Pemahaman Konsep

\begin{abstract}
This research intent to know influence methodics demonstration to stirred concept grasp object on IPA'S learning brazes IV. SDN 3 Gandusari school year round semesters 2019 / 2020. Peneltian this that is utilized which is quantitative with experiments observational type. Population in observational it is exhaustive student brazes IV. with amount 10 students. Meanwhile sample that is taken on this research 10 students. Methodic data collecting that is utilized as essays. Essay that is utilized to get data constitutes pretest and posttest. Instrumental form that is utilized which is double helix by totals problem 20 item. Base analisis already been gotten from normality quiz by use of quiz Shapiro Wilk pretest signifikan as big as 0,215>0,05. So gets to be concluded that that result gets normal distribution. Meanwhile for point posttest signifikan 0,311>0,05. So gets to be concluded that that result gets normal distribution. Meanwhile for result to test appreciative acknowledged homogeneity signifikansi Based on Mean 0,206>0,05. So gets to be concluded that data variant pretest and posttest are homogeneous (with). For hypthosts testing utilizes to test paired sample is test gotten by sig's point. (2 tailed) pretest and posttest 0,000. According to quiz pair sample t test that sig's point. ( 2 - tailed) $<0,05$ therefore get to be concluded that exist distinctive among student studying result on data pretest and posttest. Yielding thus of observational it can be concluded that exists demonstration method influence to stirred concept grasp object on IPA'S learning student brazes IV. SDN 3 Gandusari school year round semesters $2019 / 2020$
\end{abstract}

Keyword: Demonstration method, Concept grasp

91 | Pengaruh Metode Demonstrasi dengan Media Konkrit 
Pendahuluan

Negara dapat dikatakan maju bisa dilihat dan diukur dari tinnginya suatu kualitas pendidikannya. Pendidikan merupakan kunci utama sebagai kemajuan dan perkembangan bangsa yang berkualitas, dengan itu belajar merupakan suatu aktivitas yang dilakukan peserta didik dengan sengaja dalam keadaan sadar untuk memperoleh suatu konsep, pemahaman, dan pemahaman yang baru sehingga peserta didik mengalami suatu perubahan perilaku yang menjadi baik dalam berpikir, merasa, maupun bertindak. Permasalahan yang ada pada dilapangan yaitu permasalahan pada proses pembelajaranya yang kurang sesuai dengan materi dengan penyajiannya. Pembelajaran metode demonstrasi dengan media konkrit terhadap pemahaman gerak benda guru harus mengaitkan materi dengan pembelajarannya yang sesuai. Menurut susanto (2016:6) pemahaman diartikan sebagai kemampuan untuk menyerap arti dari materi atau bahan yang dipelajari, sedangkan pemahaman adalah seberapa besar siswa mampu menerima, menyerap, dan memahami pelajaran yang diberikan oleh guru kepada siswa. Sedangkan menurut
Mawaddah (2016:77) pemahaman konsep yaitu strategi dalam penyelesaiannya menerapkan konsep yang sederhana dan untk mempresentasikan konsep tersebut dan dapat diubah dalam pembelajarannya. Menurut Sanjaya (2013:152) metode demonstrasi adalah metode penyajian pelajaran dengan memperagakan dan mempertunjukkan kepada peserta didik tentang suatu proses, situasi atau benda tertentu, baik sebenarnya atau hanya sekadar tiruan. Sebagai metode penyajian, demonstrasi tidak terlepas dari penjelasan guru secara lisan. Walaupun dalam proses demonstrasi peran siswa hanya sekedar memerhatikan, akan tetapi demonstrasi dapat menyajikan bahan pelajaran lebih konkrit. Adapun menurut Wibawa (2007:117) metode demonstrasi merupakan cara mengajar guru dimana guru tersebut melihatkan, menunjukkan, proses pembelajaran sehingga siswa dapat melihat, mengamati, mendengar, dan merasakan apa yang telah diajarkan oleh guru. Sehingga pembelajaran akan dikatakan berhasil guru mengguakan media dalam pembelajaranya. Menurut Santosa dan firdausi (2016:139-145) penggunaan media pembelajaran secara maksimal sebagai salah satu sumber 
belajar dan media pengayaan. Metode Demonstrasi Dengan Media Sedangkan menurut Shoimah (2020:7) Konkret Terhadap Pemahaman Konsep media konkrit adalah sesuatu yang nyata Gerak Benda Pada siswa SD". Adapun dapat digunakan untuk menyalurkan batasan masalah dalam penelitian ini pesan dari guru kepada siswa sehingga pada siswa kelas IV SDN 3 Gandusari proses belajar mengajar akan lebih semester genap tahun ajaran 2019/2020, mudah. Sedangkan menurut Risanti menggunakan metode demonstrasi, (2013:3) media konkrit yaitu segala penelitian ini dilakukan pada Tema 8 sesuatu yang dapat menyalurkan pesan, Daerah Tempat Tinggalku Subtema 1 dapat merangsang fikiran, perasaan, dan Lingkungan Tempat Tinggalku kemauan peserta didik sehingga akan Pembelajaran 1 dan 2 Dan subtema 2 memudahkan guru dalam pembelajaran. Keunikan Daerah Tempat Tinggalku Sehingga dapat disimpulkan bahwa pembelajaran 1. Adapun rumusan media konkrit sangat membantu guru masalah ini yaitu "Apakah terdapat dalam melakukan pembelajaran agar pengaruh metode demonstrasi dengan siswa mudah menerima materi yang media konkrit terhadap pemahaman disampaikan guru. Berdasarkan hasil konsep gerak benda pada siswa kelasIV observasi peneliti menemukan beberapa SDN IV Gandusaritahun pelajaran 2020". kondisi yang kurang mendukung dalam Metode yang digunakan dalam penelitian pembelajaran karena kurangnya guru ini adalah kuantitatif.

menggunakan metode demonstrasi dimana guru masih sering menggunakan metode ceramah sehingga membuat peserta didik bisa jenuh dan pasif saat pelajaran. Sehingga penulis menggunakan media konkrit untuk menunjang keberhasilan belajar peserta didik karena dengan media konkrit peserta didik akan mengalami atau melihat keadaan yang nyata.

Dengan demikian, maka judul dalam penelitian ini adalah "Pengaruh

\section{Metode}

Penelitian Pengaruh Metode Demonstrasi Dengan Media Konkrit Terhadap Pemahaman Konsep Gerak Benda Pada Siswa Kelas IV Tahun Pelajaran 2019/2020. Menggunakan penelitian kuantitatif, metode ini digunakan untuk mengetahui pengaruh pemahaman konsep pada siswa di sekolah. Penelitian ini menggunakan pendekatan deskriptif dengan tujuan 93 | Pengaruh Metode Demonstrasi dengan Media Konkrit 
untuk mendeskripsikan objek penelitian ataupun hasil penelitian. Adapun sifat dalam penelitian ini yaitu penelitian eksperimen. Desain penelitian ini yang digunakan adalah desain preeksperiment one group pre-test-postest. Desain ini melibatkan satu kelompok dalam satu kelas dengan diberikan pretest $(O)$, diberikan treatment $(\mathrm{x})$, dan diberikan post-test. Dalam treatment ini keberhasilan ditentukan dengan cara membandingkan nilai pre-test dan nilai post-test. Tujuan dari penggunaan metode demonstrasi ini untuk mengetahui pengaruh media konkrit terhadap pemahaman konsep pada siswa.

Pada tahap pelaksanaan yang dilakukan peneliti yaitu melaksanakan penelitian pada siswa kelas IV SDN 3 Gandusari selama 3 kali pertemuan dengan membagikan soal pretest, memberikan perlakuan menggunakan metode demonstrasi berbantu media konkrit terhadap pemahaman konsep gerak benda pelajaran IPA dan melakukan posstest diakhir pembelajaran. Selanjutnya tahap pelaporan yaitu mengolah data hasil pretest dan post-test, menganalisis data yang sudah diolah, menarik kesimpulan dari data yang sudah diolah, dan melaporkan hasil dari penelitian.

Metode pengumpulan data pada penelitian ini, menggunakan metode tes. Menurut Arikunto (2013:193) tes merupakan serentetan pertanyaan atau latihan serta alat lainyang digunakan untuk mengukur ketrampilan, pengetahuan intelegensi, kemampuan atau bakat yang dimilikioleh individu atau kelompok. Bentuk tes yang diberikan adalah tes objektif berbentuk pilihan ganda yang berjumlah 20 item. Teknik analisi data menggunakan uji prasarat (uji normalitas dan uji homogenitas) dan diuji hipotesis

\section{Hasil dan Pembahasan}

Penelitian ini dilakukan pada kelas IV SDN 3 Gandusari Kecamatan Gandusari, Kabupaten Trenggalek pada kelas IV selama 3 kali pertemuan. Perlakuan metode demonstrasi terhadap pemahaman konsep gerak benda. Hasil belajar awal siswa diketahui dari hasil pretest yang diperoleh sebelum diterapkan metode demonstrasi terhadap pemahaman konsep gerak benda. Hasil pretest menunjukkan bahwa dari 10 siswa didapatkan total nilai 608 , rata-rata 60,8 , nilai tertinggi 83 , dan nilai terendah 23. Kriteria ketuntasan minimal (KKM) 
siswa yang dicapai adalah 75 dan 2 demonstrasi dengan media konkrit siswa sudah mencapai Kriteria terhadap pemahaman konsep menjadi ketuntasan minimal (KKM), sedangkan meningkat. Berikut diagram perbedaan untuk 8 siswa belum mencapai Kriteria pemahaman konsep siswa sebelum dan ketuntasan minimal (KKM). Dengan sesudah mendapat perlakuan metode demikian dapat disimpulkan bahwa demonstrasi.

setelah adanya penerapan metode

\section{Diagram 1 Hasil Pretest dan Posttest}

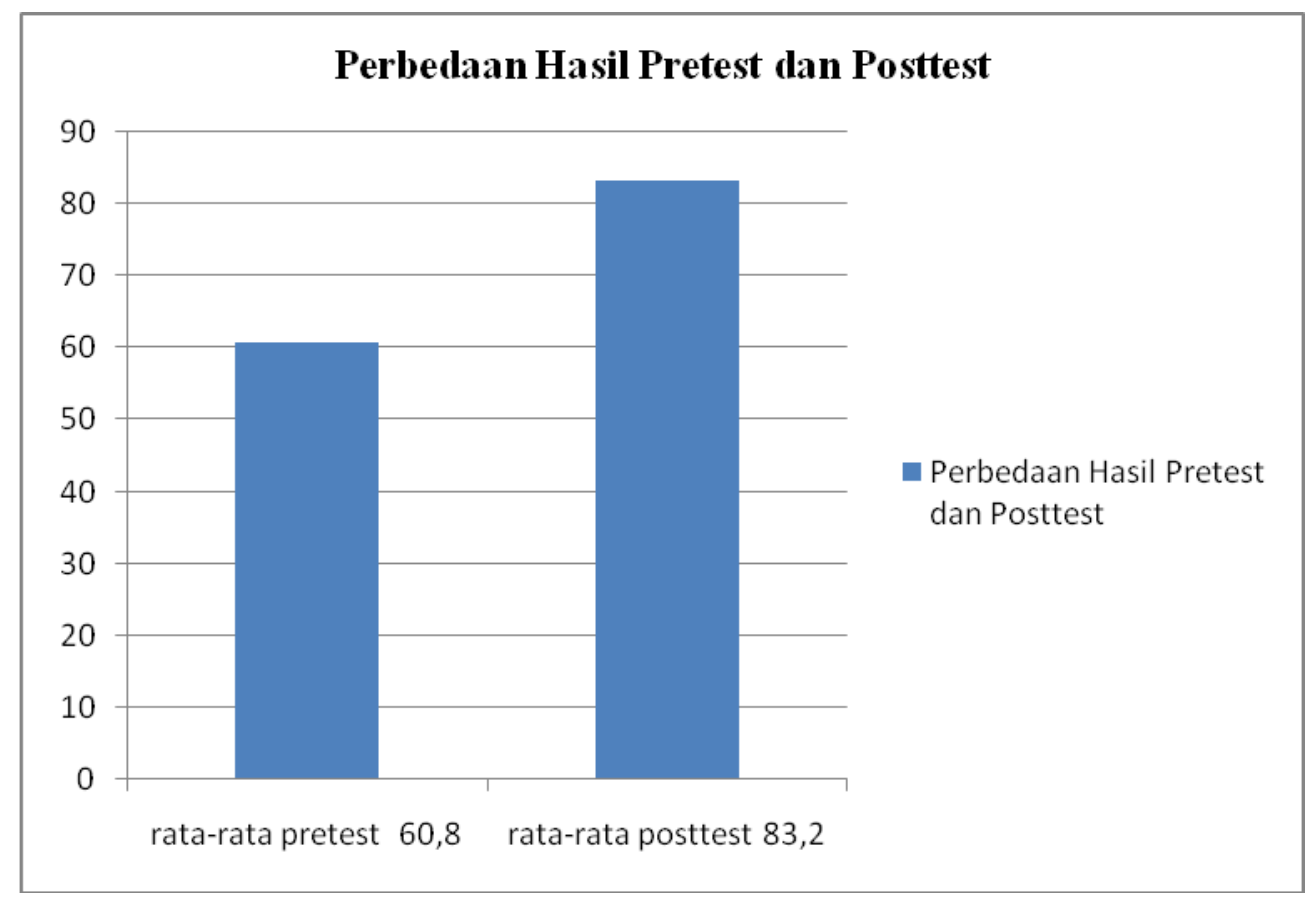

Dengan demikian dapat berdistribusi normal atau tidak. Uji disimpulkan bahwa setelah adanya normalitas dalam penelitian ini yaitu perlakuan metode demonstrasi terdapat shapiro-wilk. Ketentuannya jika sig > perbedaan pemahaman konsep menjadi 0,05 , maka data berdistribusi normal. meningkat. Selanjutnya untuk Sebaliknya, jika sig $<0,05$, maka data menganalisis data menggunakan uji tidak berdistribusi normal. Berikut hasil normalitas, uji homogenitas, dan uji uji normalitas menggunakan SPSS 25. hipotesis.

1. Uji normalitas dilakukan untuk menentukan apakah data yang diperoleh 
Tabel 4.6 Uji Normalitas

\begin{tabular}{|l|l|c|c|c|c|c|c|}
\hline \multicolumn{2}{|c|}{ Tests of Normality } \\
\hline \multicolumn{2}{|c|}{ Kelas } & \multicolumn{2}{|c|}{ Kolmogorov-Smirnov ${ }^{\text {a }}$} & \multicolumn{3}{c|}{ Shapiro-Wilk } \\
\cline { 2 - 8 } & $\begin{array}{l}\text { Statisti } \\
\text { C }\end{array}$ & Df & Sig. & Statistic & Df & Sig. \\
\hline $\begin{array}{l}\text { Pemahaman } \\
\text { Konsep } \\
\text { Siswa }\end{array}$ & $\begin{array}{l}\text { Pre- } \\
\text { Test }\end{array}$ &, 184 & 10 &, 200 &, 899 & 10 &, 215 \\
\cline { 2 - 8 } & $\begin{array}{l}\text { Pos- } \\
\text { Test }\end{array}$ &, 205 & 10 &, 200 &, 914 & 10 &, 311 \\
\hline
\end{tabular}

Berdasarkan tabel diatas, maka varians yang sama atau tidak. diketahui nilai signifikan untuk kelas Ketentuannya yaitu apabila nilai $>0,05$, pretest adalah 0,215 $>0,05$. Sedangkan maka data berasal dari varian yang nilai posttest $0,311>0,05$. Sehingga, sama. Sedangkan nilai $<0,05$ maka data dapat disimpulkan data tersebut tidak berasal dari varian yang sama. berdistribusi normal karena nilai Adapun hasil uji homogenitas dari data signifikan dari keduanya $>0,05$. SPSS

2. Uji Homogenitas

Uji homogenitas bertujuan untuk mengetahui data tersebut diambil dari

Tabel 4.7 Uji Homogenitas

\begin{tabular}{|c|c|c|c|c|c|}
\hline \multicolumn{7}{|c|}{ Test of Homogeneity of Variance } \\
\hline \multicolumn{2}{|c|}{} & $\begin{array}{c}\text { Levene } \\
\text { Statistic }\end{array}$ & df1 & df2 & Sig. \\
\hline $\begin{array}{c}\text { Hasil } \\
\text { Belajar } \\
\text { Siswa }\end{array}$ & Based on Mean & 1,725 & 1 & 18 &, 206 \\
\cline { 2 - 6 } & Based on Median & 1,118 & 1 & 18 &, 304 \\
\cline { 2 - 6 } & $\begin{array}{c}\text { Based on Median } \\
\text { and with adjusted df }\end{array}$ & 1,118 & 1 & 12,206 &, 311 \\
\cline { 2 - 7 } & $\begin{array}{c}\text { Based on trimmed } \\
\text { mean }\end{array}$ & 1,540 & 1 & 18 &, 231 \\
\hline
\end{tabular}

Berdasarkan output di atas diketahui nilai varian data pretest dan posttest adalah signifikansi Based on Mean 0,206 > homogen (sama). 0,05. Sehingga dapat disimpulkan bahwa 3. Pengujian Hipotesis 
Setelah dinyatakan data pretest dan posttest berdistribusi normal dan homogen (sama), maka langkah selanjutnya yaitu uji hipotesis. Uji hipotesis yang digunakan dalam penelitian ini adalah uji Paired Sample $T$ Test digunakan untuk mengetahui pengaruh metode demonstrasi dengan media konkrit terhadap pemahaman konsep gerak benda tematik siswa kelas IV SDN 3 Gandusari. . Berikut rumusan hipotesisnya.
1. $\mathrm{H}_{\mathrm{a}}$ : Terdapat pengaruh penerapan metode demonstrasi terhadap pemahaman konsep gerak benda pada pembelajaran IPA kelas IV SDN 3 Gandusari.

2. $H_{\circ}$ : Tidak terdapat pengaruh penerapan metode demonstrasi terhadap pemahaman konsep gerak benda pada pembelajaran IPA kelas IV SDN 3 Gandusari

Tabel 4.8 Uji Paired Sample T Test

\begin{tabular}{|c|c|c|c|c|c|c|c|c|c|}
\hline \multicolumn{10}{|c|}{ Paired Samples Test } \\
\hline & & \multicolumn{5}{|c|}{ Paired Differences } & \multirow[b]{3}{*}{$\mathrm{t}$} & \multirow[b]{3}{*}{ df } & \multirow{3}{*}{$\begin{array}{l}\text { Sig. (2 } \\
\text { tailed) }\end{array}$} \\
\hline & & \multirow{2}{*}{$\begin{array}{c}\text { Mea } \\
n\end{array}$} & \multirow{2}{*}{$\begin{array}{l}\text { Std. } \\
\text { Devi } \\
\text { ation }\end{array}$} & \multirow{2}{*}{$\begin{array}{l}\text { Std. } \\
\text { Error } \\
\text { Mean }\end{array}$} & \multicolumn{2}{|c|}{$\begin{array}{l}95 \% \text { Confidence } \\
\text { Interval of the } \\
\text { Difference }\end{array}$} & & & \\
\hline & & & & & Lower & Upper & & & \\
\hline $\begin{array}{l}\mathrm{Pa} \\
\text { ir } \\
1\end{array}$ & $\begin{array}{l}\text { Pre } \\
\text { Test } \\
- \\
\text { Post } \\
\text { Test }\end{array}$ & $\begin{array}{l}70, \\
500\end{array}$ & $\begin{array}{c}19 \\
064\end{array}$ & $\begin{array}{c}4,26 \\
3\end{array}$ & $\begin{array}{c}61,57 \\
8\end{array}$ & $\begin{array}{c}79,42 \\
2\end{array}$ & $\begin{array}{c}16,5 \\
39\end{array}$ & 19 & 000 \\
\hline
\end{tabular}

Berdasrkan output pada tabel 4.8 menerapkan metode demonstrasi dalam diperoleh nilai sig. (2-tailed) pretest dan pembelajaran dan sudah menerapkan posttest 0,000 . Sesuai dengan uji pair metode demonstrasi.

sample t-test bahwa nilai sig. (2-tailed) < a. Dengan demikian adanya perlakuan 0,05 maka dapat disimpulkan bahwa menggunakan metode demonstrasi terdapat perbedaan antara hasil belajar terhadap pemahaman konsep gerak siswa pada data pretest dan benda terdapat perbedaan yang posttest.dapat diketahui pengaruh meningkat. Penelitian sebelumnya perbedaan rata-rata, berarti ada dilakukan oleh Penelitian yang dilakukan perbedaan pemahaman konsep sebelum oleh Rodiyah (2015) metode 
demonstrasi dalam pembelajaran elemen gerak tari mata pelajaran seni budaya siswa kelas $7 a$ SMPN 26 Semarang. Hasil penelitian ini menunjukkan bahwa menggunakan penerapan metode demonstrasi didukung metode ceramah dan dibantu media LCD.

b. Penelitian ini dilakukan oleh Kurniawan (2015) dari fakultas Ekonomi Universitas Negeri Yogyakarta dengan penelitian yang berjudul "Penerapan Metode Demonstrasi Pada Mata Pelajarankearsipan Guna Meningkatkan Prestasi Belajar Siswa Kelas X Kompetensi Keahlian Administrasi PerkantoranSMK YPE Sawunggalih Kutoarjo". Rata-rata nilaiketuntasan siswa pada siklus I sebesar (81,57\%)mengalami peningkatan padasiklus II menjadi (89,47\%).

\section{Kesimpulan}

Berdasarkan hasil penelitian pada skripsi ini, maka dapat disimpulkan pengaruh metode demonstrasi terhadap pemahaman konsep gerak benda pada siswa kelas IV SDN 3 Gandusari. Hal ini diketahui dari peningkatan pemahaman konsep siswa pada rata-rata hasil pretest sebanyak 60,8, sedangkan pada hasil posttest diperoleh rata-rata sebanyak
83,2 . Sehingga dari nilai rata-rata tersebut menunjukkan bahwa hasil posttest mengalami peningkatan yaitu sebesar 22,4.

Berdasarkan hasil penelitian metode demonstrasi terhadap pemahaman konsep gerak benda pada penelitian ini perbaikan pembelajaran dapat disarankan yaitu bagi guru, agar guru dapat menerapkan berbagai metode dalam pembelajaran untuk lebih bervariasi dan inovatif yang dibutuhkan oleh siswa sehingga tujuan belajar dapat tercapai dengan yang diinginkan. Sehingga melalui metode demonstrasi terhadap pemahaman konsep gerak benda ini dapat dijadikan alternatif pada pelajaran IPA dan pelajaran yang lainnya, bagi siswa, agar lebih semangat dan serius dalam belajar untuk mencapai kriteria ketuntasan minimum (KKM), serta lebih meningkatkan cara siswa belajar, bagi sekolah, diharapkan untuk menambah sarana prasarana pembelajaran seperti alat peraga, media, dan guru yang telaten, karena dengan hal ini akan menambah sekolah lebih maju untuk kedepannya, bagi peneliti selanjutnya, dengan adanya penelitian ini diharapakan dapat memberi referensi untuk kedepannya agar dapat diterapkan. 


\section{DAFTAR PUSTAKA}

Ahmad Susanto, M. P. (2016). Teori belajar dan pembelajaran di sekolah dasar. Kencana.

Firdausi, R., \& Santosa, A. B. (2016). Pengembangan Media Pembelajaran Mobile Learning Berbantuan Smartphone Android Pada Mata Pelajaran Perekayasaan Sistem Antena Studi Pada Siswa Kelas XI TAV SMK Negeri 1 Nganjuk. Jurnal Pendidikan Teknik Elektro, 5(1). https://jurnalmahasiswa.unesa.ac.id/index.php/jurnal-pendidikan teknikelektro/article/view/13758

Arikunto, S. 2010. Prosedur Penelitian Suatu Pendekatan Praktik. Jakarta. Bumii Aksara.

Kurniawan. 2015. Penerapan Metode Demonstrasi Pada Mata Pelajaran Kearsipan Guna Meningkatkan Prestasi Belajar Siswa Kelas X Kompetensi Keahlian Administrasi Perkantoran SMK YPE Sawunggalih Kutoarjo. Fakultas Ekonomi Universitas Negeri Yogyakarta. http://eprints.poltekkesjogja.ac.id/1595/

Mawaddah, S., \& Maryanti, R. (2016). Kemampuan Pemahaman Konsep Matematis Siswa SMP dalam Pembelajaran Menggunakan Model Penemuan Terbimbing (Discovery Learning). Edu-Mat: Jurnal Pendidikan Matematika, 4(1).

https://ppjp.ulm.ac.id/journal/index.php/edumat/article/view/2292

Risanti, N. M. N. (2013). Penerapan Metode Pemberian Tugas Berbantuan Media Konkrit Melalui Kegiatan Finger Painting Untuk Meningkatkan Perkembangan Sosial Emosional. Jurnal Pendidikan Anak Usia Dini Undiksha, 1(1). https://ejournal.undiksha.ac.id/index.php/JJPAUD/article/view/1001

Rodiyah, S. (2015). Metode Demonstrasi Dalam Pembelajaran Elemen Gerak Tari Mata Pelajaran Seni Budaya Siswa Kelas VII A SMP Negeri 26 Semarang (Doctoral dissertation, UNIVERSITAS NEGERI SEMARANG). https://lib.unnes.ac.id/22045/

Sanjaya, Wina. 2016. Strategi Pembelajaran. Bandung: Prenadamedia Group.

Shoimah, R. N. (2020). Penggunaan Media Pembelajaran Konkrit Untuk Meningkatkan Aktifitas Belajar Dan Pemahaman Konsep Pecahan Mata Pelajaran Matematika Siswa Kelas III MI Ma'arif Nu Sukodadi-Lamongan. Mida: Jurnal Pendidikan Dasar Islam, 3(1), 1-18.

https://scholar.google.co.id/scholar?hl=id\&as_sdt=0\%2C5\&q=Shoimah\%2C+R .+N.+\%282020\%29.+Penggunaan+Media+Pembelajaran+Konkrit+Untuk+Men ingkatkan+Aktifitas+Belajar+Dan+Pemahaman+Konsep+Pecahan+Mata+Pela jaran+Matematika+Siswa+Kelas+III+MI+Ma\%E2\%80\%99arif+Nu+SukodadiLamongan.+Mida\%3A+Jurnal+Pendidikan+Dasar+Islam\%2C+3\%281\%29\%2 $\mathrm{C}+1-18 . \& b \operatorname{tnG}=$ 
Rizka Janawati Mita Arsih, dkk.

Wibawa, C. (2007). Perbedaan efektifitas metode demonstrasi dengan pemutaran video Tentang pemberantasan dbd terhadap peningkatan pengetahuan dan Sikap anak sd di kecamatan wedarijaksa kabupaten pati. Jurnal Promosi Kesehatan Indonesia, 2(2), 115-129.

https://ejournal.undip.ac.id/index.php/jpki/article/view/2553 